\title{
REMOVE FIVE TIMES MORE PLAQUE THAN MANUAL BRUSHING
}

Available with a specially designed Orthodontic Tip, the Waterpik Water Flosser is the ideal oral hygiene solution for patients seeking to improve their oral health during orthodontic treatment, and is supported by a wealth of scientific evidence.

In a study conducted by Sharma et al. (Am J Orthod Dentofacial Orthop 2008; 133: 565-571) patients who used a Waterpik Water Flosser after brushing removed up to three times more plaque than those who brushed and used floss, and up to five times more than those who only used manual brushing alone.
Waterpik International, Inc. supplies a range of oral hygiene devices designed to meet all your patients' needs. These include models such as the easy to use Cordless Plus Water Flosser, and the high specification Ultra model which features state-of-the-art Water Flosser technology and provides the ultimate in oral hygiene performance.

For more information on Waterpik Water Flossers speak to your wholesaler or visit www.waterpik. co.uk. Waterpik products are widely available in Boots stores.

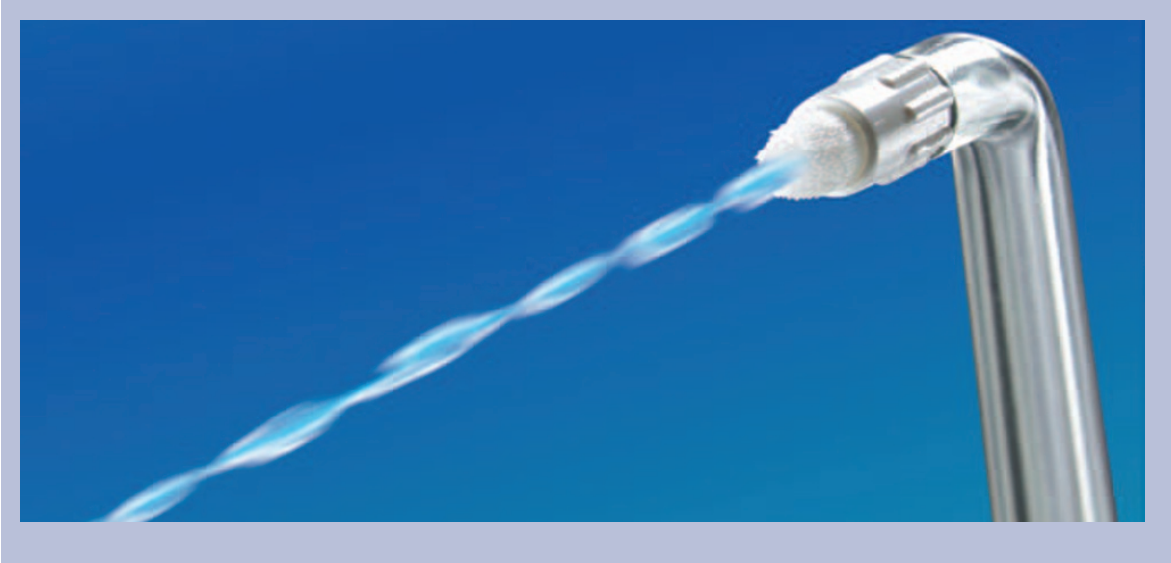

\section{SWEETENED BUT GOOD FOR TEETH}

Providing effective solutions to help patients maintain good oral health, Spry's xylitol-based Dental Defence System range is quickly growing in popularity, including 100\% xylitol sweetened chewing gum, mints, sweets, toothpaste, mouthwash and dry mouth spray.

Several clinical studies have proven that xylitol not only inhibits the metabolism of the oral bacteria responsible for dental plaque, but reduces plaque levels by $50 \%$.

Patient compliance with Spry xylitol products is high as the products are available in popular flavours, and patients can also choose between the different products to ensure regular use.

Spry products are suitable for all patients regardless of age, physical ability or personal preferences.

For more information, call Anyone 4 Tea Ltd on 01428 652131, or visit www. anyone4tea.com.

\section{WITHDRAWAL NOTICE}

The Sharps Terminator, a device designed to easily destroy needles after use and reduce incidence of needlestick injuries (featured in the $B D J$ product news in July 2012: Hasta la vista, needle; BDJ 2012; 213: 34), has been withdrawn from sale in the UK and Germany by VLA Healthcare.

The decision to remove the product from sale and to cease all promotional activity was taken due to concerns over reliability and performance issues pertaining to the product, which were uncovered during NHS testing and evaluation.

The company said that it was 'committed to supplying high quality products and services and as such, is working with other manufacturers to develop alternative solutions to Sharps Terminator'. Feedback on the product had been positive but the product could only destroy certain types of needles. 